The Classic:

\title{
The Museum IN THE FOURTH DIMENSION
}

\section{Hugues de Varine}

The necessity of renewal: It is not long since the modern museum was born, the offspring of international museological research in combination with isolated museographic experiments. To a large extent the journal Museum published by Unesco has been the scene of its birth and the means of its dissemination. Other publications, countless conferences, and the work of institutions in process of renewal have been determining factors for studies, confrontations and improvements. But more still remains to be said, and we may wonder whether this modern museum, or at least the museology which backs it up, is anything more than a formal - not to say formalisticgroping after reform, when what is wanted is a totally and radically new institution.

In other words, is the modern museum really a new product? Or is it no more than an old product in a new package? The everyday experience of the visitor to the museum, as of the museological or museographic expert, would incline them to opt for the second alternative, while many theorists would like to have us believe in the first. But we must not rest content with pretences, or with a certain ease of conscience, however high a level it may emanate from.

When we try to reduce the museology of today to a few simple concepts, to its first principles, we can make out three basic elements:

a) the object, or the real thing, as Duncan Cameron brilliantly defines it: the renewal of the concept of the collection by reducing it to the sole notion which is truly characteristic of the museum that it is devoted to things;

b) time - not only past time, the worship and the evocation of which lay at the origin of the first museums, but the time dimension, embracing the present and future in a view which is now dia-

The Museum in the Fourth Dimension presenterades för deltagarna i ICOM-Ceca konferensen Museernas roll i en decentraliserad kulturpolitik i september 1976 (20 år sedan!)

i Umeå. En dansk översättning av texten finns i Dansk Tidsskrift forr Museumsformidling 4 (1979) s. 61-65. 
52 chronic, now synchronic, as Georges Henri Rivière will have it ;

c) space, which replaces the object in its unique situation as part of a meaningful whole owing its existence to the action of nature, man, or the gods.

Never until these last few years has analysis of the premises of museology been pushed so far. Unfortunately, thinking has always confined itself to the museum as a thing, the museum as an institution, and, in an utterly sterile fashion, the museum's public. Why this check? Why have museologists failed in their mission to renew the museum, to adapt it to the modern world? Because, in my opinion, they have ignored, without exception and systematically, what I shall call the fourth dimension of the museum, its social dimension.

The object of the museum, what it is made for, is not the visitor, tourist, student, scholar, amateur, or casual passer-by; it is the whole community, both immediate and more remote.

The subject of the museum, that which makes it, is not a collection, a scientific discipline, a curator, or an administrator; it is, once again, the whole community.

In short, the justification for the existence of the museum is the service it renders society, and this alone. Thus, it is society which should be asked what it expects of the museum, how it intends to integrate the museum into its life.

Having advanced this postulate, the only one capable of opening up a truly new perspective to museological research, I wish to try to draw from it two conclusions, which are in fact no more than two directions of theoretical and practical research.

\section{A DATA BANK}

Our society, like each one of us, needs a constant flow of information, data, on which it builds the world, founds our culture, and creates our future. Science supplies us with abstract elements, in written or diagrammatic form; the mass media bring us fleeting, pre-digested impressions; everyday life offers us experience, individual or collective, but always subjective; future and present alike confront us with problems. Only the museum can also store the things which represent at once our heritage and our technology, which reflect both research and experience, the fruits of all natural and human activity and store them in their complete, threedimensional form, referenced and documented in time and space.

Thus, what society asks of the museum, of all museums regardless of size, specialization, or wealth, is that they should act as banks of things, objects, real data, just as a computer, in its more limited way, can store data which may be coded, written, or diagrammatic. Of course, the museum is a bank by virtue of its collecting and classifying functions, but also by virtue of its role in communication and dissemination, in order to meet all the demands of users with varying needs.

Consequently, the museums serving a given community must together make up - in the form of objects, real things, documented and immediately utilizable - a concrete picture of man's ecology, and be the source of the cultural materials which the community will work up, assimilate, and then use in tomorrow's social construction. Since the exhaustive, objective collection, in the old sense, can only con- 
tain objects which have lost their functional or ritual value, this means that the museum as bank of things must burst its bounds to include - in spatial terms - the whole of its community; and the real things which it accumulates must not be in effect laid aside in a building dedicated for this purpose, but must count as virtually and scientifically belonging to the museum collection, though without having to give up their physical location or their usefulness.

In concrete terms, every thing that exists is a potential museum object. A small number of these things, because they are in some way representative, significant, aesthetically interesting, rare, or fragile, are acquired and preserved as part of the public heritage, to ensure that they will be permanently accessible. A larger number are catalogued, indexed, either systematically for the information of the community or in lots for the purposes of specialized scientific research projects, but without seeking to secure ownership of them.

This global concept is indeed difficult to conceive of in today's situation, and for people - the "curators" - who have been brought up on the notions of the collection and the masterpiece, of preservation and presentation. And it is difficult to integrate in a legalistic administrative and economic system, which recognizes and accepts no other point of view than the ownership of cultural wealth.

\section{A COMMUNITY UNIVERSITY}

But we should not satisfy ourselves with a passive consumption of three-dimensional data, and this regardless of the scope we may allow to the concept of the collec- tion, as we have already seen. Society is essentially the creator of its own culture, and while the data bank is necessary, it is not sufficient. It needs also the complex alchemy which, starting with isolated elements - raw materials, in a sense - makes it possible to take initiatives, to construct fitting solutions to the problems man faces in his natural and social environment. Hence the idea that the museum is and should be, in the full sense of the word, the university of our time: the place which can and must mirror the questions which individuals and social groups are asking themselves - not to supply answers, but to state the problems, point to alternatives, and offer materials and information to assist them to realize and decide what attitudes to take up. Nothing that is human should be foreign to the museum. It speaks a privileged language the antidote to the two-dimensional culture of the written word and the picture, a return to what is concrete and real, the chance to escape ready-made arguments, to arrange the terms in an order of one's own, to go back and stop - in a word, the language of the museum is the liberation of the mind.

The reader will have noticed that neither in the preceding paragraph nor in this do I distinguish between classes of museums, between disciplines, whether specializations of museums or of learning. I find no need to do so, because the traditional classifications, in the form in which they are respected by national or international professional organizations, or in which they obstinately figure in course manuals and conference programs, are secondary to the museum - their only function is to assist in the subdivision of collections and their administrative 
54 attachments. They are no more than convenient pigeon-holes, at the level of the data bank, useful as specialized university departments are useful, but profoundly deceptive when one is seeking to grasp the reality of the museum.

For if the community is one, the university-museum must be conceived and realized as a single entity. It must find the means of attaining this - I make no claim to settle the question here - having regard for one purpose only - service. Not the service of more or less undifferentiated visitors, of a formless or captive public, and not the service of that non-public which polarizes all the frustrations and guilt-complexes of the activators of our day. But the service of society, or more exactly of the community from which the museum issues. Thus the museum will no longer need to stick to mirroring the research of its curators, the increase or the strong points of its collections, or fashionable intellectual topics. It will take its keynotes from the problems of presentday man, from the lines of force existing in the life of the community, from the dialectical relations between man and his environment. To do this, like every tool of education and development, like the traditional university, it will have to struggle constantly to be objective, independent, and representative. The important thing is not that it should achieve this completely, but that it should be felt and seen to be faithfully striving to do so.

\section{THEORY INTO PRACTICE}

Now, the reader will say, it is time to abandon utopia and give a little thought to practice. Indeed, the above is dictated more by the task of defining a new approach for the museum institution than by pragmatic considerations applicable directly to museums as we know them. On the one hand, I believe that such a radical rethinking is the only possible salvation for the museum as a useful factor in the life of society in the modern world. Utopia is no danger as long as it is aware of itself and inspires positive action with concrete effects. On the other hand, old and recent experience proves that the above museological principles are practicable and effective. Natural history museums are in part data banks, as are the falsely named museums of archaeology and some museums of national ethnography. An increasing number of attempts at global community activation by means of the language of the museum (neighbourhood museums in the United States, écomusées in France, local and school museums in Mexico) demonstrate the "university» aspect. The écomusées are perhaps the only systematic attempt to link both functions, and one or two of them actually succeed. But this is obviously not enough, and we must not content ourselves with isolated experiments, even successful ones. So let us try to follow up the argument.

\section{TRANSFORM WHAT EXISTS}

The 15,000 or 20,000 museums operating in the world today must naturally be neither destroyed nor renamed. Nor must they henceforth dedicate themselves to the exclusive service of tourists and aesthetes. They constitute a potential network, with close-knit meshes covering the whole territory of certain European and American countries. Invaluable collections, buil- 
dings, and dedicated staffs are a considerable capital, to be deployed anew prudently yet progressively. This can be done by an action on three planes:

1) on the personal level, by systematically recycling decision makers, agents, research workers, activators, and by proper training of future "curators», in order to create a new mentality and a new competence - that of being at the service of the public and at the disposal of society;

2) on the administrative level, by acting on the structural relations among museums (eliminating the compartmentalization of learning and strengthening the co-ordinated network of institutions) and on the links of responsibility between the community and its museums (by granting representatives of this community a real part in defining the programs and the actual management of the museums);

3) on the level of the characteristic image of the institution, by using existing buildings, workshops, and personnel as a dynamic resource radiating over the whole community, by breaking with the concept of the closed collection, by breaking the walls of the activity rooms, by changing the topics of work (to be chosen in the community instead of in the museum).

\section{INNOVATE}

I believe it is time for every country which possesses a certain number of museums, and which wants to pursue a modern museum policy which is open to the future, to establish a pilot museum sector, to serve as a field of experiment, as an internal pedagogical tool for the profession, and as a public demonstration. This sector would collect the professionals most gifted with creative imagination, driving spirits from other fields but also capable of innovation, and also, of course, considerable material and financial resources. It would consist, firstly, of a few traditional institutions in which significant upheavals could be produced, and, secondly, of "neomuseums» located in communities representing the problems of modern society (suburbs, industrial cities, homogeneous rural regions, etc.).

This pilot sector, free of the administrative and professional constraints which entrammel museums, would be given the task, over a sufficient length of time, of working out completely realistically the possible variants of the museum of the future, especially with reference to community participation and to the realization of the bank of objects.

All over the world, but especially in north-western Europe and Latin America, I have met very many museologists who would be only too happy to launch out in this direction, if only they could count on, if not the support, at least the benevolent neutrality of government and municipal authorities. Now that the traditional or even modernized museum risks being no more than a tourist-trap or an annexe to the classroom - that is, turning to a captive public since it can find nothing else to do - it is time to start searching, soberly and intelligently, yet resolutely and persistently, for the formulae - not 
Hugues DE VARINE

56 magical but practical - which will restore to man and the community the free use of this set of real things which make up their natural and cultural environment.

Unless all the world's museologists get down to this task, the branch on which they are sitting will continue rotting to its heart.

NOTE

English translation: Kim Bastin 